\title{
Enabling Physical Collaboration in Industrial Settings by Designing for Embodied Interaction
}

\author{
Daniel Fallman \\ Interaction Design Lab, Umeå Institute of Design \\ Department of Informatics \\ Umeå University, SE-90187, Umeå, Sweden \\ +46907867030 \\ daniel.fallman@dh.umu.se
}

\begin{abstract}
We describe the efforts of bridging a fieldwork study which used ethnographic techniques at two industrial assembly sites into a functional prototype for service and maintenance work. The primacy of the human body and the mobile nature of such activity are put forward as important design incentives, which guides the design of the mobile support system. The situatedness in the physical world is proposed to enable service technicians to continue to collaborate in a way which is in line with their current work practice, permeated by physical collaboration, having presence in the world, and human-to-human interactions.
\end{abstract}

\section{Keywords}

Physical Collaboration, Mobility, Embodiment

\section{INTRODUCTION}

Computer-Supported Collaborative Work (CSCW) has since its origin as a field in the mid-80s been concerned with understanding the practices of people at work, and by turning this understanding into the design of novel computer systems [1]. Early on, studies showed that work is everything but its naïve interpretation of individuals hired by organizations to carry out specific sets of structured tasks according to prescribed procedures. Rather, early influential ethnographic studies, including [2, 3, 4], showed that work on the contrary is something carried out by individuals or groups of people acting as members of and within social community, where their activities are locally situated, difficult to define, document, and impose in operational terms, and highly interactive to its nature. Semantically, a shift of focus then occurred when CSCW designers moved from talking about automating human activity to consider information technology (IT) instead as tools for supporting human work $[5,6]$.

Undoubtedly, these seminal efforts for the CSCW commu- nity still make us question a simplified notion of what work is all about. It has helped us take a step back from the traditional dichotomy of studying man-machine interaction which still permeates a great deal of research within the Human-Computer Interaction (HCI) community, helping us consider and expand on issues on a level of the social and the organizational. While the findings of these studies have been of great influence, it must be realized that work in these cases is often reduced to office work, and thus the concept of workers abridged to office workers. Given the history of computing, it should not come as a surprise that efforts within $\mathrm{CSCW}$ started from within the white collar world. After all, the offices of the world trade in the concept of information, and the computer is the means by which information is handled.

In this light, this paper differs from most previous as well as current efforts within the CSCW community. First, our study does not focus on white collar workers, as it describes the efforts involved in a project where a fieldwork study using ethnographic techniques at two industrial assembly manufacturing sites influence the design of a mobile computer-based collaboration tool for service technicians.

Second, while some authors note that work in industrial settings have come to resemble office work in some respects [7], we insistently argue some perceived differences in the work carried out by the studied service technicians and that what is expected of office workers, and argue that these differences should be capitalized on in an appropriate design of a computer support system. Here we will specifically focus on the issue of physicality that pervades service and maintenance work, and how it is not generally supported by the traditional notion of CSCW applications.

Third, as the concept of computing in general and the desktop computer in particular has been developed to support office work, we feel the need to question the presuppositions we have about the role of the computer in workrelated activities. Our study has shown that what the service technicians crave is not a mobile office, but rather a system characterized by a high level of collaborational potential, while demanding low physical and mental attention 
to assist with both highly specific as well as fairly general issues, far from the scope of any imaginable mobile office solution.

Hence, the distinctiveness of this study is not just that our focus is on an unconventional group of users, but also that our prototype system questions the role the computer ought to play in work-related activity. We have found that altering the role of the computer-that is thinking of the computer in different terms, trying to grasp "what it is", and imagining what it "could be"-from that of a desktop computer substitute to a computer-based tool specifically for service work has opened up the window of opportunity for a different kind of collaboration to emerge between people than the kind of collaboration pursued by for instance groupware or instant messaging applications.

\section{SCOPE AND PURPOSE}

In brief, the scope of this paper is to describe how in this project a fieldwork study of a particular work practice was used to inform the design of a mobile support system for service technicians. The fieldwork has provided us with both a conception of the context and environment in which work is carried out-e.g. what it is like to work as a service technician, what kind of problems they wrestle with, and how they related to other groups of workers at the sites - as well as specific design incentives which have motivated new design solutions by aggravating sediment conceptions of mobile information technology.

In this, we describe how we have tried to find ways to allow the current work practice, permeated by ad-hoc collaboration both with other service technicians but also with other categories of workers, to continue to flourish even though computer support is added.

In carrying out this project, we have come to accept as true that the way service technicians think about themselves and their work is centered on the concept of being mobile, that is being able to move around freely and have ad-hoc interactions with people in order to keep the production line in operation, for the best of the organization. From this, we understand that any design must capitalize on mobility and the fluctuating interaction that occur between people with different responsibilities, and that we should strive to avoid designs which confine service technicians to decontextualized, office-like environments, which unfortunately is precisely what their current support systems do.

Consequentially, we have come to consider collaboration in this setting not only in terms of for instance sharing information, awareness, or asynchronous communication. While these features have their place also in settings far from the office environment, we suggest that what is meant by collaboration may differ substantially between different work practices. The collaboration that takes place between the pitcher and the backstop in a game of baseball is not the same kind of collaboration as that which occurs between two researchers writing a paper. Through our study, we have found that supporting collaboration in the setting of service technicians is more like the first than the latter. Thus, in this paper, the focus is specifically on the study of the work practice of the service technicians, and how it influenced the design of the mobile IT support tool not only to sustain and support but also to strengthen the collaborative nature of work as it was understood to be carried out by the service technicians.

\section{Paper Structure}

Next, we will briefly introduce our theoretical base and discuss related work in the field of CSCW and HCI. The section entitled Bridging Fieldwork and Design will then in some detail give an account of the fieldwork study and how our analysis has focused on the work practice of the service technicians, and explain how incentives from this study has been drawn on during the development of the prototype, both in conceptual, physical, interactional, and functional terms. In this, special focus will be given to the inherent collaborative nature of the work carried out by the service technicians, and how it has come to permeate the prototype design. Under Enabling Collaboration, we discuss how our prototype differs from existing support systems, and how we believe our reconceptualization of the role of the computer in service related activity enable and support collaboration at these sites. The paper then ends with a conclusive section, summarizing the findings of the study.

\section{THEORETICAL AND METHODOLOGICAL BACKDROP}

In this work, we have been influenced by the phenomenological concept of embodiment introduced by MerleauPonty [8] and Heidegger [9], and interpreted by [10, 11, 12, 13, 14, and 15]. According to Dourish [15], drawing primarily on Mearleau-Ponty's Phenomenology of Perception, embodiment is the property of through one's body being manifest within the world and hence inevitable a part of it. It is important to note that the concept denotes not only physical embodiment, but also many other aspects of our everyday world. Dourish suggest that embodiment represents a participative status rather than simply a physical 'there' [15]. According to this view, interaction is an embodied phenomenon, as it happens within the world, and that the world-which is both physical and socialprovides the circumstances which give interaction its meaning and value in a given situation. The objective of the study of embodied interaction is thus to establish an understanding of how computing is intertwined with human users and the world. In this study, we particularly focus on the role of the human body in that relationship

Through its different understandings, embodiment has formed the core component of phenomenological thought since its origin in the early twentieth century. In this study, we have been looking to put the phenomenological understanding of embodiment to use by specifically applying it to interaction with computer systems. The result may be interpreted as forming embodied interaction. While [15] explores embodied interaction in the context of social com- 
puting and tangible interaction, our intention is to extend his conceptualization into the domain of mobile computing.

\section{Ethnography in CSCW}

In recent years within $\mathrm{CSCW}$, HCI, and design research, there has been a turn away from formal methods of understanding work, such as Task Analysis [16], towards more sociology-oriented methods of inquiry. Here, ethnographic techniques have been used as a means for forming adequate understandings about the nature of work in particular settings, to form a foundation for the design of interactive systems. Our analysis is further influenced by ethnomethodology $[15,17,18]$ which concentrates on the actual practices of people engaged in activity within the world. The relationship between computer systems design and ethnomethodology is explored by [19].

Ethnography is an observational technique that from a naturalistic perspective is concerned with giving an account of a certain domain of life from the perspective of the people involved in that domain $[16,20]$. The role of the researcher is to participate in people's daily lives - in this case their life at work - with the purpose of collecting firsthand experiences of how people experience their involvement in the world, by listening to what people say, watching what happens, and asking contextual questions $[21,16]$. Significant examples of ethnography related to CSCW include [18] [22], [23] and [24]. Suchman [18] studied the troubles involved in using a photocopier, showing the way that the complexity and context dependency of even seemingly simple tasks go well beyond the point of decomposition and specification. Heath \& Luff's [22] study of the London Underground line control room shows how ethnography may inform design of novel interactive systems. Important accounts of the usefulness of ethnography in CSCW design is also evident in the studies on air traffic controllers [23] and police work [24].

\section{Mobility in CSCW Research}

Significant contributions to the introduction of mobile computing to the field of CSCW has been made by [25] [26] [27] [28] and [29] Based on their study of a spatially distributed product design team, Bellotti \& Bly [25] argue mobility to be essential for communication and for use of shared resources. Mobility within the realms of a particular site was found to facilitate useful informal interactions and awareness of a kind which was unavailable for colleagues working at remote sites. Luff \& Heath [26] provide an oversight of three studies which each focus on different aspects of supporting mobility within collaborative work, and how in each of these settings mobility is found crucial for collaborative work.

Moving closer to setting and aim of our study, Kraut et al [30] provides a description of a design of a collaborative, mobile computer system for field repair and maintenance of mechanical devices, where the maintenance personnel where able to retrieve help from remote experts by use of different kinds and quality of video and audio communica- tion. Several authors, such as $[31,32,33,34]$, too notice the value of collaboration when troubleshooting and repairing complex technological equipment. Further examples of $\mathrm{CSCW}$ research involving mobile IT in non-office settings are [35], focusing on support of process engineers at wastewater plants; industrial process plants [36]; and airport snow crew [37].

\section{BRIDGING FIELDWORK AND DESIGN}

To be able to gain at least an initial understanding of what work is like in the blue-collar, industrial world, we thus need to learn more about this setting, and to do this we need to turn to these future users of our system's design and learn how their problems differ from the nuisances of traditional office workers. What is it like to be a service technician? What role could a future mobile support system play in this work? What functionality would be suitable to implement in this setting? With what do service technicians currently experience problems? Hence, we set out to try to understand the service technicians in terms of their work practice, which is their thoughts and actions in a social and organizational setting, i.e. how people actually go about their everyday work, solve problems, and keep the organization operative. In accordance to this need, we conducted a fieldwork study which used ethnographic techniques at two large industrial manufacturing units; Volvo Trucks in Umeå and Volvo Cars in Gothenburg, both of which are large Swedish vehicle assembly manufacturing industries. We followed closely and took notes of literally everything that service technicians did during entire shifts, including communication with other service technicians, other personnel such as line operators and managers, as well as any external contacts. As in all qualitative work, we must to a large extent rely on our own interpretations of what was going on-i.e. we have no direct link to the consciousness of the subjects - but we also constantly asked contextual questions and chatted with the service technician in order to find out what their interpretations were of what was happening, and if, when, and how it was different from our understanding of the situation.

Hence, in this study, we have deliberately chosen a naturalistic perspective, not to rely on formally set up interviews with service technicians, line operators, and managers. Be argue that interviews tend to be most useful for finding out how things should be carried out, e.g. in this case how specific work procedures have been prescribed to be carried out by-the-book - which in fact also may be how service technicians themselves think they carry out them-rather than on how things actually are performed - the practices that makes an organization work, or e.g. what a service technician really do to solve a specific problem. Hence, we were interested in what they do, which other actors do they communicate with and for what purpose, what problems to they face on a daily basis, how and with whom they collaborate, and so on. In short, the focus of the field study was to form a sturdy understanding of the work practice of the service technicians, in order to see how these could be 
supported by a mobile IT implementation, focusing on issues of mobility and collaboration, without turning them into work procedures.

\section{Findings that Influenced Design}

A basic finding, but which is important for the whole of the project, was that the service technicians we studied already use a number of mobile technology devices. There are of course the traditional physical technology, such as hammers and screwdrivers, but we found also two instances of omnipresent mobile information technology. The first of these is the service technicians' use of short-wave radios. These are always switched on and employed to send out emergency requests or other sorts of general information which everyone working at a particular moment should receive. Second, the service technicians are also equipped with cordless digital telephones used for person-to-person communication, frequently used for communication with managers, planning personnel, other service technicians, line operators, and external contacts. At both sites visited, the short-wave radio and the cordless telephone were the mobile information and communication devices in use today. In addition, many of the service technicians where found to be carrying their own, personal cellular phones, also during work. They seemed to be frequently used both for making personal calls, but also for work related or semi-work related purposes, such as talking to family, friends, or for calling colleagues on holiday.

In brief, a vehicle assembly factory generally consists of a number of cells arranged in some order to form a production line. Every cell has one or more specific purposes, which must be completed in order to proceed to the next cell. Every cell in turn consists of a number of components. Components are manufactured by a number of different vendors, and range from small lifts, transporters and power outlets to complicated electronics and robotics.

Contrary to our initial beliefs, we found that service technicians do not generally repair factory components that break down on the site. Especially so for electrical and electronic components, erroneous apparatus are instead replaced, i.e. put out of production, and then sent away for repair, either locally or remotely. This suggests that the need in for a system that provides mobile access to manuals and extensive help on specific repair work issues (cf. [34]) would be little needed. Our interpretation is that this setting it is more suitable to equip the service technicians with help on how to locate, remove, install and replace components, than being able to browse documentation about specific components on the site.

Rather than extensive use of manuals, the service technicians tended to rely on two main principles for solving issues such as not knowing how to handle a component, or for troubleshooting disorderly apparatus. The first strategy involved the use of large graphical blueprints, rather than manuals. The reason for this seemed to be the manuals' focus on objects, i.e. in detail describing particular compo- nents, while actual problems and breakdowns in fact often seemed to endure in-between specific components. It seemed to be that the connections between components, including power supply, oil supply, water supply, etc., that was the most frequent cause of breakdowns, not the components themselves. The various kinds of manuals that were available did not seem to have this focus on connections and links between components, at least not in a way that the service technicians seemed to benefit from, which left the manuals largely unused in favor of the processoriented blueprints.

Second, if a component broke down that the service technicians did not know how to handle, they frequently used their internal mobile digital phones to immediately place a call, either to other service technicians, or to the manufacturer of the specific component. Again, these communicatory measures were taken instead of trying to find the right piece of information in the extensive manuals. They seemed to take comfort in the interactionary nature of speaking to a real person about the sometimes time-critical work they had to carry out. By communicating with others, they also had access to certain kinds of knowledge not attainable through manuals, such as the possibility of direct feedback; knowledge of common problems; the possibility of being redirected, and so on. Hence, two possible design incentives emerge from these two principles; one would be to equip the service technicians with digital access to blueprints rather than written manuals, and the second to provide quick and effortless communication access to other service technicians and manufacturers of components.

One of the biggest concerns we found the service technicians to have was the awareness, locating, and handling of spare parts. When something broke down in the industrial production line, a service technician were contactedeither informally by line operators through telephone or more formally by the service technicians' managers or special factory monitoring personnel over the short-wave radio - and usually headed in the direction of the breakdown to see what was that cause. Usually, this resulted in the service technician either being able to quickly solve the problem at the site, or find out that a defective component needed to be replaced, or that the problem did not resist in a quickly perceivable specific component and that the problem required some more attention. But if the component was found in need of being replaced, there was generally no computer system available at neither of the two sites studied that would allow a service technician to check whether or not there were corresponding spare parts in stock. At this stage, the service technicians could do one of two things. First, they could head to an office-like environment to use a desktop computer based system to find out whether or not such spare parts were in fact available, or if it would have to be ordered. This was found to be the most common approach. As a second and less frequently employed approach, the service technician could call or 
head toward the stockroom to find out in person the status of the spare part needed, or she could try to contact some of the stock-room personnel by use of the digital phone.

A design incentive here, as we interpret it, is to give the service technicians fast and effortless access to what is kept in the stock, so that for every component there is a direct link to the number of such components available in stock, and that there is a possibility of quickly placing an order of such components if they were missing. The fact that the service technicians would know if there were any spare parts available would also give them the opportunity to chose whether or not they should try to repair on-site, or if they should immediately replace the malfunctioning device with an existing spare part, and trouble-shoot the malfunctioning component off-line.

Several service technicians commented at numerous occasions that they in this particular situation would benefit largely from some sort of history access of each component or cell. We interpreted this as a call for access to a list of every maintenance and service events for each component. For instance, a specific part of a component had needed to be replaced numerous times in a short period of time, it would probably be that the malfunctioning was not so much in the small part itself but rather that the cause of the problem might persist somewhere else. The problems causing the same part of a component to break down might for instance remain somewhere else than in the component, and hence the whole component could be replaced to check if that was the case. If the problem still endured, it seemed likely that the cause of the breakdown of a specific component was the result of a malfunctioning or bad tuning of another component somewhere else in the cell or elsewhere along the production line. To assist in these kinds of considerations, the service technicians expressed a need to access a history function for each component, which would make every replacement, maintenance or repair activity on the specific component explicit.

During the study, we several times came across the expressed need of some sort of notice board for the service technicians. These would allow them to collaborate in an uncomplicated and direct fashion, by giving each other small notes and information about what has happened, who had done what, what was the likely cause of potential problems, etc. We found that at many times glitches and malfunctioning within a specific cell were not obvious or directly solvable phenomena. Although each service technician usually had an opinion or an idea about what was really the cause of the problem, often there was just not enough time to look more closely into the matter and hence those ideas where often lost, or at least not communicated with other service technicians. Sometimes a service technician might have done something to a component-for instance made some sort of undocumented, temporary solution-just before leaving for the day, and hence remained unknown to the other service technicians. At a number of occasions, some time was spent not on correcting a malfunction but on figuring out how another service technician had implemented the temporary solution.

At one of the two sites, there were in fact ordinary, physical notebooks scattered throughout the factory with the intent to allow service technicians to express these issues. After reviewing them, we found that they remained largely unused. A possible reason for this seemed to be that the notebooks were not really physically located close to the corresponding assembly cell being the focus of attention; instead they were found in a somewhat odd, quasi-office environment forming an "office island" in the vicinity of the production line, but embodying neither the office environment nor the production line environment. Here, our design incentive has been to let the assembly cells themselves embody these notebooks by introducing a virtual, context-sensitive notebook application as a service of the prototype system, in order to move the notebooks closer to what they describe. This system automatically assigns any notes a service technician makes to a location in time and space, according to where the service technician is located in the factory. Hence, this makes it possible to attach a virtual note directly to a specific component or cell, i.e. a location in physical space. Also, by the modality change of making the notes virtual, the service technicians can access all these notebooks through the same device, and hence the effort needed to take part in the discussion or take small notes of one's activities is smaller.

Finally, and somewhat surprising, we found that one of the largest problems within the service work as a whole was as simple as lack of knowledge about where other people were physically located, and what their telephone numbers were. The service technicians at one of the sites especially gazed in awe at their managers whom benefited from the use of Palm Pilot PDAs, with which they had been equipped to ease communication with customers and external contacts. But the result of this introduction of PDAs to managers was that if service technicians, or line operators for that sake, needed to quickly find a number to another service technician, manufacturer of a specific component, or anyone else, it was not unusual that the nearest manager was asked to look it up.

While this seemed to be a real need, the current workpractice-including finding and bothering managersseems not very productive. A design incentive here would be to equip the service technicians with a list of useful telephone numbers, which could draw on other features of the system and benefit from partitioning, such as separating between which service technicians are currently working, i.e. which are currently active in some sense, and which are not available, and from knowledge about other service technicians' physical location. Further partitioning could be based on e.g. managers, foremen, planning personnel and manufacturers of components. 
Obviously, the findings reported on in this section represent only a small part of the study as a whole, but can be considered the most distinctive ones in terms of constituting design incentives, both for the system seen from a single-user perspective and from a collaboration perspective. One of the most important parts of doing a observational study is not only to find design incentives and problems in the current work practice, but it is also to get to know the intended users, the context of work and the environment in which the work is being carried out. This contextual knowledge, which remains largely implicit and difficult to express, also influences design to a great extent and is as such as necessary as the findings that have been presented which deals with specific issues.

\section{PROTOTYPE DESIGN}

From the findings reported in the previous section, we have designed and implemented a prototype system for mobile support of service and maintenance work in industrial assembly settings. Our aim was to design and implement a functional prototype to be evaluated in production work, which challenged both the interaction and interface paradigms of current mobile information technology, as well as provided the platform for exploring a way to achieve collaboration between the users.

\section{Prototype Design Vision}

The design vision for the prototype we have developed can be summarized as: A PDA-based, arm-worn, and contextually aware system supporting a small set of useful and interconnected activities for collaborative service and maintenance work in industrial assembly settings.

Hence, our vision has been that of an "intimate computer" which is mounted on and remains at the user's arm at all times. In terms of technology, the prototype is based on a horizontally aligned Compaq iPaq ${ }^{\mathrm{TM}}$ handheld computer, typically known as a PDA, which is fixed on a physical glove like configuration typically worn on a right handed user's left arm.

Physical pointing and proximity is the major style of interaction, enabling the user to interact in an exceptionally direct sense with objects in the physical environment by literally pointing directly at them in the physical world. This view of pointing in the physical world contrasts sharply with how pointing usually proceeds in interaction with computers, where the user traditionally controls a virtual pointer which is used to select virtual objects. But since service work is largely concerned with physical objects, we found it unnecessary to provide any virtual replicas of these objects; instead we allow users to point directly at physical objects using their hands, to initiate interaction. This follows the overall design goal to pursue the notion of embodied interaction, allowing the service technicians to act directly in the physical world, which undoubtedly is their primary world of concern, avoiding a drift off into a virtual mirror world. Technically, this is implemented by using a Radio Frequency Identification
Tag (RFID) reader mounted on all prototypes. The tag reader reads tags that have been previously attached to objects throughout the factory. RFID tags are cheap, small, and do not require their own batteries. The device then communicates the identification number received from the RFID tag to a server though a wireless LAN connection, which in turn sends back information about the particular object at which the user is pointing, and provides a central system knowledge about the position of the user.

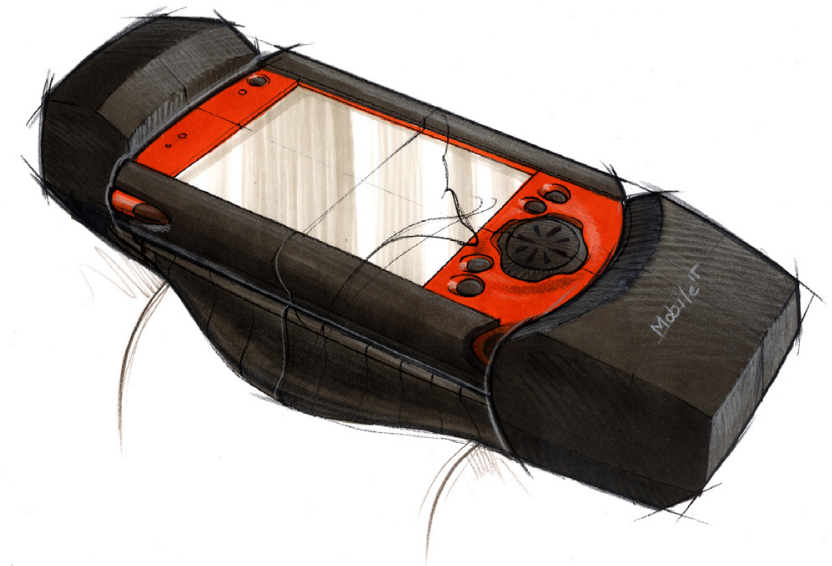

Figure 1. Sketching the prototype system

\section{Description of the Prototype System}

Rather than implementing a prototype system that captures all the functionalities, services, and features a service technicians may ever need - such as web browsing, tools for financial plans, and word processing-following the idea of the mobile computer as a desktop computer substitute, we have chosen to pursue a view of what functionality to offer the user which is more in line with Norman's [38] notion of an information appliance, to pursue a more humane, unobtrusive and invisible model of computer use, drawing on the notion of embodied interaction. Appliances are devices designed to perform specific functions, or has a small set of interconnected functionality, and which do so efficiently and with little conscious effort from the user [39]. Information appliances are also defined as being designed to support specific activities, but specialize in information [38]. In the project, we have also come explore the tension between the single-function ideal of the appliance, and the possibilities of interconnections that IT makes possible. This is a delicate matter, as too many interconnections seems to make the device intrinsically more complex to use, and introduces a barrier of abstraction between the user and the world, which is exactly what we are trying to get away from by pursuing on the concept of embodied interaction. Too few interconnections, however, seem to conflict with some inherent properties of information technology, that information can be shared, transformed, and communicated.

The functionality the prototype system supports can be divided into two groups. First, we have contextually unaware functionality, which is functionality unaware of 
physical location or context, and as such are available for use at all times. Second, the contextually aware functions on the contrary provide functionality that is directly connected to phenomena in the physical world, with which the user interacts by pointing at them. An early design idea was to not just add another mobile information device, used on the side of using the private mobile telephone many service technicians carried, the in-house digital phone, and the short wave radio, but rather implement the functionality of all these devices into a single form factor. By doing this, we both avoid what we call the "Christmas tree" effect, as well as open up possibilities for making simple but highly useful interconnections between these devices. As an example of an omnipresent function independent of context, the prototype system provides the user with list of contacts in different categories, such as active service technicians, managers, and external contacts. As the digital telephone and the mobile device are combined, it becomes an easy task to first locate a contact in the list, and then quickly select a contact in the list and automatically place a call, without dialing any numbers or manually having to transfer information between two devices.

Technically, the telephone's microphone and speaker have been placed on the wrist side of the arm, making the transition easy from placing a call to speaking. However, as service technicians in some occasions would benefit from having both hands available for physical work, e.g. when getting remote expert guidance in a difficult maintenance activity, we have begun testing alternative hands-free solutions.

This design choice is influenced by the high level of acceptance of telephony as the accepted means of communication in the industrial world. What strikes one that enters this setting from the academic world is the ubiquitous nature of telephony, everyone from managers to line operators, from external contacts to clients seems to uses them at every possible occasion. This obviously provides an incentive for not introducing collaborative means of other modalities in this setting, such as for instance emailing, instant messaging, video conferencing, etc. Another incentive for not designing means of communication in more traditional computational terms is twofold. First, text input and text output is difficult in general for handheld devices, as there are many problems concerning small displays and that there is no simple means of entering text into a mobile system [40]. Second, reading and entering large amounts of text was found inapt for the current industrial environment where lightning conditions vary substantially. Communicating with voice rather than by means of written language also make it possible for the service technicians to be intentional on objects in the physical world, rather than being forced to switch their attention between looking at the computer device and looking at the physical world.

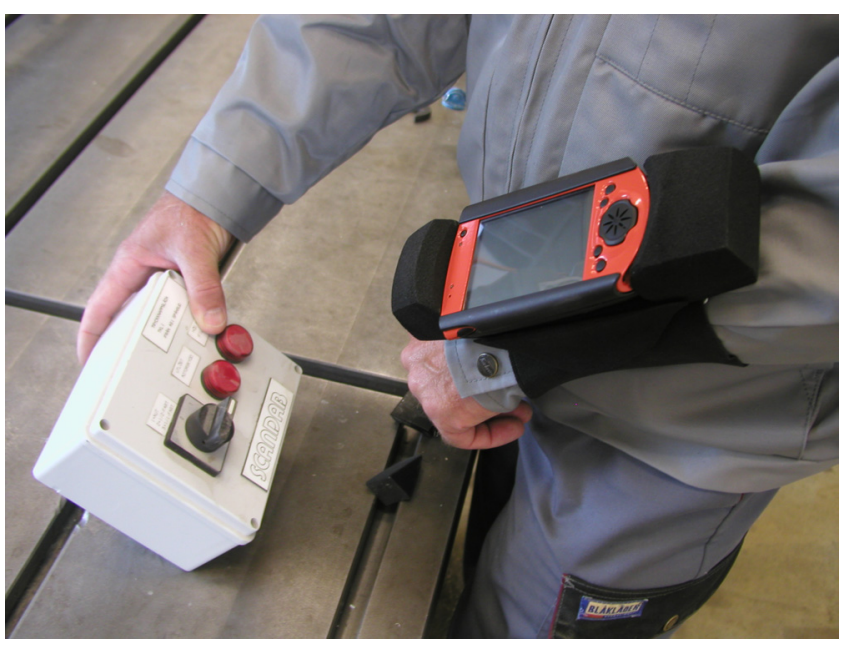

Figure 2. The arm-worn prototype system in use

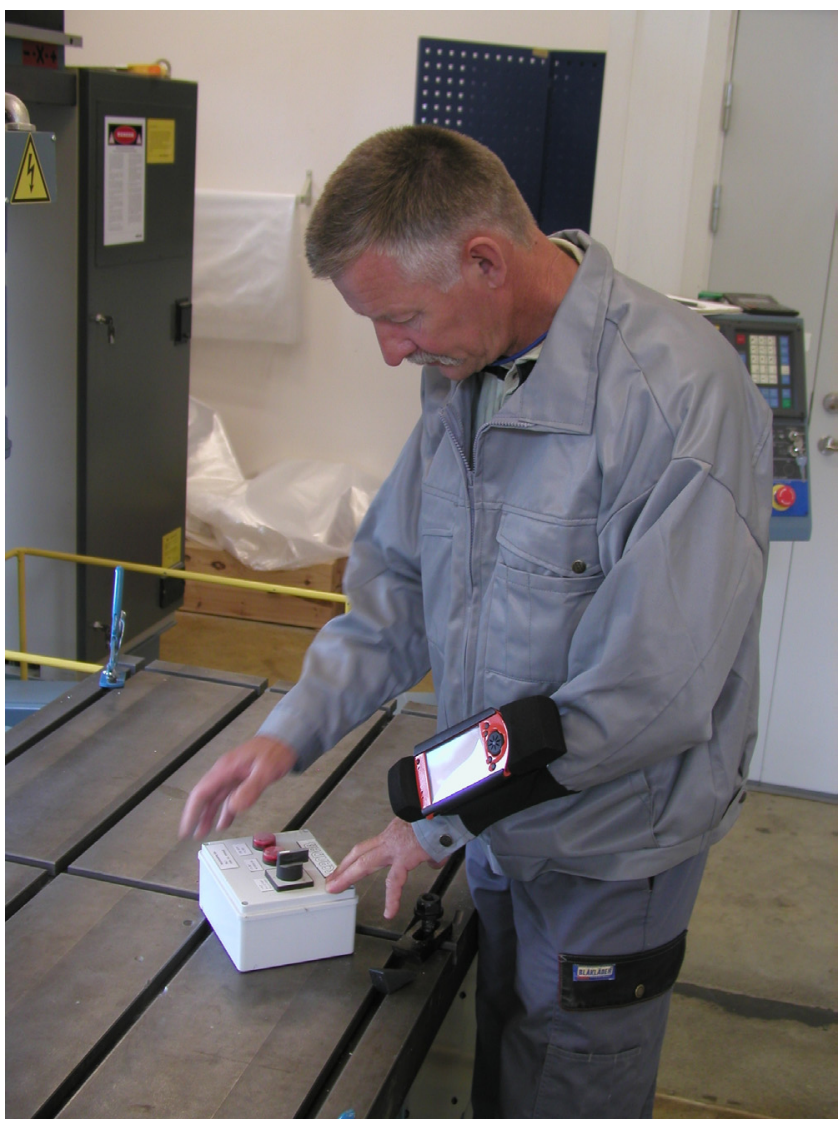

Figure 3. Allowing service technicians to be out where they want to be, located physically on site, in sight.

In addition, by introducing the functionality of the shortwave radio into the mobile device, we may also spot several additional benefits. First, the prototype is able to communicate the emergency call to its user in more than one modality. While the short-wave radio is audio only, the mobile device is able to communicate emergency calls using three different modalities; sound, vision and force feedback. 
The basic set of functionality also includes a list of tasks, but a list which is contextually aware. By the use of the RFID tags, a central server system knows the position of the service technicians within the factory, which makes it possible this list of tasks to be updated dynamically to suggest potential tasks to the service technicians based on physical location. Tasks in this sense indicate primarily pre-planned activities such as regular maintenance or monthly checks, which are often not time-critical or immediately needed for ongoing production. The system thus only suggests possible tasks based on what needs to be done and different service technician's physical location. We have found it very difficult to get acceptance from the users of a system which assigns tasks to them involuntarily. Instead, the tasks are not assigned but instead accepted or ignored by the particular service technician in the particular situation, and the decision of whether or not to accept a task is thus made according to information that a technological system based on for instance coordination theory would never have access to; e.g. social issues such as conversations and personal issues such as stress and repetitious work. Initial tests have suggested that the acceptance of a system using a non-deterministic assignment of tasks is far greater than a corresponding involuntarily system of assigning tasks.

A major aim with the whole project is to find a way to alter the experience of using a computer system. This design choice has thus been made also to move from a conception of using a system that does not belong to me, but rather exists somewhere else, and hence is under the control of and belongs to someone else, which originates in the history of computing, where computers were few, large, and expensive. As an alternative experience, we want to provide a system which is embodied, not only in a physical sense, but also in a conceptual sense. Our design strives to give the users the experience of having a system that are theirs; a system which is on their side. Later, we will describe how this conception or experience of using the system also provides the foundation for collaboration in this setting.

When the service technicians wander within the assembly site, tracked ubiquitously by the RFID tags, particular functionality connected to certain objects in the physical world becomes available. This availability of functionality based on physical proximity resembles how we interact with objects in the physical world, and as such efficiently and effortlessly limits the complexity of the computer system. As the user can only interact with a limited amount of objects at any given location, the design do not need to provide design means for a great level of complexity at the interface level. This allows the interface and the interaction style to be developed with a low level of abstraction [40].

The most common physical objects that service technicians interact with through physical proximity is the component. Every component has attached to them a small set of virtual functionality and information. First, information is made available about the actual component itself. The device recognizes automatically which component it is in terms of name, model, internal identification number, manufacturer, external contacts to that manufacturer, its placement in the factory, and its current status. An important finding of the ethnographic study was the fact that service technicians rarely use manuals for components. If there is any doubt on how to operate, repair or replace a specific component, service technicians prefer to call the manufacturer and ask, rather than looking into manuals or other kinds of documentation. Hence, the prototype does not in a direct way include support of viewing or browsing documentation, instead, following the service technicians' work practice, the design allows the service technicians to easily connect specific components to the component manufacturer's phone number in the external contacts list.

Second, there is also a history function connected to each component, which allows the service technicians access to all previous maintenance and service that has been carried out on this particular component, within a configurable time span. The main incentive to this function comes unswervingly from the ethnographical study, as introduced in a previous section. This list includes information about who has carried out the last activity, and the system provides the means for placing a call to this person directly, e.g. to discuss what was done, why it was done, etc. It is intended to be a resource for the service technicians, as a useful tool for finding out why certain components break down and needs to be replaced every now and then. As been implied earlier, glitches in the production line system often seem to occur in between components, lingering in the interfaces between different components and in the supply of external electricity, oil, air, and water. The service technicians have the knowledge, skills, and experience needed to solve these kinds of problem, or put differently, locating and settling these kinds of problems is the definition of being a service technicians. We consider the act of trying to replicate this skill and knowledge in a computer system to be very difficult. Instead, we have chosen to focus on supporting the skills of the service technicians, i.e. assisting them in doing their work, rather than try to replicate or model their skills and knowledge in the computer. Hence, our design is a system for experts, rather than an expert system [41]. As introduced earlier, every component and every cell also has its own virtual notice board, where service technicians may leave small notes, e.g. to explain what has been done and why this action was taken, or to give one's view of what may be wrong. We are currently experimenting both with scribble-like notes written directly on the screen, and voice memos.

In summary, the functions provided form support of a small set of closely related activities, with a strong focus on supporting the current work practice, i.e. how work is actually carried out by the service technicians studied, with a special focus on designing for enabling collaboration. 


\section{ENABLING COLLABORATION}

We propose this system as beneficiary for the collaborative nature of the service technicians' work practice for a number of reasons. Undoubtedly, collaboration between service technicians is largely situated in the physical world. From the fieldwork study, we have a number of findings that support this claim. The service technicians' shared objects of concern are often physical objects, and frequent discussions take place between service technicians in the physical proximity of the concern. Service technicians sometimes need to use their bodily skills and strengths to lift or maneuver devices, and they often show each other how something is done in a very direct sense, for instance explaining how a robot is to be reprogrammed by showing how it is done. From this it is easy to extract the importance of the body in this type of work; a primacy of bodily concerns largely different from the concerns of the body that we encounter in the white-collar world [42]. But as introduced earlier, it is the white-collar world that has been the major influenced to research and design in the area of CSCW. We found that the primacy of the body and the service technicians' way of direct involvement with the physical world should form the starting point of our design efforts. To allow the service technicians to operate directly on the world, we should not tie them to a specific location in the way a desktop computer ties its users to a desk, or the way a notebook computer ties its users to the nearest flat surface. In direct involvement with the world, the concept of mobility seems crucial, and the implementation of a system mounted on the user the unsurpassed solution.

We argue that the situatedness of the service technicians in the physical world enables them to continue to collaborate in a way which is in line with their current work practice. This is not done directly through additional functionality built into an existing computing device, such as instant messaging, shared documents or whiteboards, and visualized awareness of location are added to a desktop computer system. Rather, our approach is to consider the work practice as it is currently established, and from this try to support the way collaboration is already taking placepermeated by physical presence. Hence, by designing a low attention, mobile, and arm-worn intimate system we make it possible for the service technicians to continue to cooperate in the same physical sense as they are used to, while at the same time give the service technicians access to computational services and information.

These services and the information they carry are today only found in desktop computers, where the service technicians need to step away from the site, into an office-like environment, where they sit down, typically in solitude, to find the right piece of information in a myriad of different computer systems. With the embodied interaction approach, we believe collaboration is made possible through the design of the system, making it relevant for the CSCW community, but not in the traditional sense of adding features to existing computing environments. As service technicians need access to virtual information and benefit from functionality made possible by the use of a computer, it seems not to be the question whether or not they should be equipped with or have access to computational power, but rather how their system should be designed to suit their work the best. Hence, our design is intended to allow service technicians to collaborate in the physical world, supporting collaboration as much through what it is note.g. obtrusive, complex, stationary, in need of constant attention, etc - as through what it is. The prototype gives the service technicians access to useful information and services, but does so in a way which enables them to function and play an active role in the physical and social world. For the service technician, it is in this world that collaboration takes place.

\section{CONCLUSIONS}

In this paper, we have described the efforts involved in bridging a fieldwork study, using ethnographic techniques, of the work practice of service technicians at two industrial assembly sites into a functional prototype for service and maintenance work. The tendency of CSCW to focus on the white-collar office work has also been noted, and arguments and empirical findings have been provided as to why some of the underlying differences between office work and the blue-collar world of the service technicians need to be capitalized on in such a computer based system. As the most prominent difference, we have put forward the role of the human body in service and maintenance activity, and how we believe our prototype system design drawing on the phenomenological notion of embodiment has reconsidered the character of a computer system, providing a case in point system which embodies a role better suited for the activity in which it is put to use, as well as acknowledging the primacy of the body in service and maintenance work.

The situatedness of the service technicians in the physical world has been proposed to enable them to continue to collaborate in a way which is in line with their current work practice, permeated by physical collaboration, presence inthe-world, and human-to-human interactions. Our prototype design is thus primarily intended to allow service technicians to collaborate in the physical world, and not in a virtual world. While the prototype gives the service technicians access to useful information and services, it does so in a way which enables them to function and play an active role in the physical and social world, thus opening up the window for collaboration in the physical world.

\section{ACKNOWLEDGMENTS}

The two projects which have enabled the writing of this paper are fully funded by ABB through Umeå Center for Interaction Technology (UCIT) at Umeå University, Sweden. The author is also grateful to Volvo in Umeå and Gothenburg, and to the work of Staffan Eriksson, Niklas Andersson, Anders Hasselqvist, Thomas Lundqvist, Björn Yttergren, Alistair Regan, and Prof. John A. Waterworth. 


\section{REFERENCES}

1. Bannon, L. CSCW: An Initial Exploration, Scandinavian Journal of Information Systems, vol. 5, 1993, 324

2. Gerson, E. \& Star, S. Analyzing Due Process in the Workplace, ACM Transactions on Office Information Systems, vol. 4, no. 3, 1986. 257-270

3. Suchman, L. Office Procedures as Practical Action, ACM Transactions on Office Information Systems, vol. 1, no. 4, 1983. 320-328

4. Wynn, E. Office Conversation as an Information Medium. Ph.D. Dissertation, University of California, Berkeley, CA, 1979

5. Woo, C. \& Lochovsky, F. Supporting Distributed Office Problem Solving in Organizations. $A C M$ Transactions on Office Information Systems, 4:3, 1986, 185-204

6. Hewitt, C. Offices are Open Systems., ACM Transactions on Office Information Systems, 4:3, 1986, 271287

7. Hellman, R. Combining CSCW and user support techniques to design collaborative user interfaces, Interacting with Computers, 4:1, 1992, 41-67

8. Merleau-Ponty, M. Phenomenology of Perception, Eng. transl. by Smith, G, Routledge, London UK, 1962

9. Heidegger, M. Being and Time, orig. 1927, Eng. transl. by Harper and Row, New York, 1962

10.Varela, F., Thompson, E. \& Rosch, E. The Embodied Mind: Cognitive Science and Human Experience, MIT Press, Cambridge MA, 1991

11.Lakoff, G. \& Johnson, M. Philosophy in the Flesh, Basic Books, New York NY, 2000

12. Sheets-Johnstone, M. The Roots of Thinking, Temple University Press, Philadelphia PA, 1990

13. Dreyfus, H. The Current Relevance of Merleau-Ponty's Phenomenology of Embodiment, In Haber \& Weiss (Eds.), Perspectives on Embodiment, Routledge, London UK, 1996

14. Robertson, T. Cooperative Work and Lived Cognition: A Taxonomy of Embodied Actions, in Proceedings ECSCW'97 (Lancaster, UK). Kluwer, Dordrecht, 1997

15.Dourish, P. Where the Action Is: The Foundations of Embodied Interaction, MIT Press, Cambridge MA, 2001

16. Hughes, J., King, V., Rodden, T., and Andersen, H. The Role of Ethnography in Interactive Systems Design, interactions, vol. 2:2, 1995, 56-65

17. Garfinkel, H. Studies in Ethnomethodology, Prentice Hall, Englewood Cliffs NJ, 1967

18. Suchman, L. Plans and Situated Actions, Cambridge University Press. Cambridge, 1987
19.Dourish, P. \& Button, G. On Technomethodology: Foundational Relationships Between Ethnomethodology and System Design, Human-Computer Interaction, vol. 13:4, 1998, 395-432

20. Hughes, J., Randall, D., \& Shapiro, D. From Ethnographic Record to System Design: Some experiences from the Field, Computer Supported Cooperative Work, 1993, 1: 123-141

21.Hammersley, M. \& Atkinson, P. Ethnography: Principles in Practice, $2^{\text {nd }} E d$, Routledge, London, 1993

22. Heath, C. \& Luff, P. Collaboration and Control: Crisis Management and Multimedia Technology in London Underground Line Control Rooms, Journal of Comp. Supported Cooperative Work, 1:1, 1992, 24-48

23. Bentley, R., Hughes, J., Randall, D., Rodden, T., Sawyer, P., Shapiro, D., \& Sommerville, I. Ethnographically-informed systems design for air traffic control. Proceedings of CSCW'92, ACM Press, New York NY, 1992, 123-129

24. Ackroyd, S., Harper, R., Hughes, J., Shapiro, D., \& Soothill, K. New Technology and Practical Police Work, Open University Press, Milton Keynes UK, 1992

25. Bellotti, V. \& Bly, S. Walking away from the desktop computer: distributed collaboration and mobility in a product design team, Proceedings of CSCW'96, ACM Press, Cambridge, MA, 1996, 209-218

26. Luff, P. \& Heath, C. Mobility in Collaboration. Proceedings of CSCW (Seattle, WA), 1998, 305-314

27. Kristoffersen, S. \& Rodden, T. Working by Walking Around. Requirements of Flexible Interaction Management in Video-supported Collaborative Work, In Spence, B. \& Winder, R. (Eds.) Proceedings of Human Computer Interaction, Springer Verlag, 1996

28. Kristoffersen, S. \& Ljungberg, F. Supporting Mobility, Coordination and Sharing in Dispersed, Networking Groups, Proceedings of the Fifth International Conference on Information Systems Development, (Gdansk, Poland), 1996, 339-354

29. Wiberg, M. \& Ljungberg, F. Exploring the Vision of Anytime, Anywhere in the Context of Mobile Work, in Knowledge management and Virtual organizations: Theories, Practices, Technologies and Methods, Brint Press, 2000

30. Kraut, R., Miller, M. \& Siegel, J. Collaboration in performance of physical tasks: Effects on Outcomes and Communication, Proceedings of CSCW'96, ACM Press, Cambridge, MA, 1996, 57-66

31.Cash, J., O’Neil, J. \& Ostrofsky, K. Otis Cash, Elevator Co.: Managing the Service Force. Harvard Business Case 9, Cambridge, MA, 1991, 191-213

32. Orr, J. Sharing Knowledge, Celebrating Identity, In Middleton, D. \& Edwards, D. (Eds.) Collective Remem- 
bering: Memory in Society. Sage Publications, London UK, 1990, 169-189

33. Sachs, P. Transforming Work: Collaboration, Learning, and Design. Com. of the ACM, 38:9, 1995, 36- 44

34. Smailagic, A., \& Siewiorek, D. A Case Study in Embedded Systems Design: VuMan 2 Wearable Computer, IEEE Design and Test of Computers, 10:4, 1993

35. Bertelsen, O \& Nielsen, C. Dynamics in Wastewater Treatment: A Framework for Understanding Formal Constructs in Complex Technical Settings, Proceedings of ECCW'99, Kluwer Academic Publishers, London UK, 1999.

36. Nilsson, J., Sokoler, T., Binder, T., Wetcke, N., Beyond the Control room: Mobile devices for spatially distributed interaction on industrial process plants. HUC2000. Proceedings of the Second International Symposium on Handheld and Ubiquitous Computing, Springer, 2000
37. Juhlin, O. \& Weilenmann, A. Decentralizing the Control Room: Mobile Work and Institutional Order. Proceedings of ECSCW'01 (Bonn, Germany), 2001

38. Norman, D. The Invisible Computer, MIT Press, Cambridge MA, 1998

39. Mohageg, M. \& Wagner, A. Design Considerations for Information Appliances, In Bergman, E. (Ed.) Information Appliances and Beyond, Morgan Kaufmann, San Francisco CA, 2000, 27-52

40.Fallman, D. Wear, Point, and Tilt: Designing Support for Mobile Service and Maintenance in Industrial Settings, Proceedings of DIS2002 (London UK), 2002

41. Hirschheim, R. \& Klein, H. Four Paradigms of Information Systems Development, Communications of the $A C M$, vol. 32(10), 1989

42.Zuboff, S. In the Age of the Smart Machine, Basic Books, New York NY, 1988 